\title{
Design of a cultivator mounted on a tractor with a power of up to $20 \mathrm{~kW}$
}

\author{
Jarosław Selech ${ }^{1, *}$, Dariusz Ulbrich ${ }^{1}$, Włodzimierz Kęska ${ }^{1}$, Żaneta Staszak $^{1}$, Jacek \\ Marcinkiewicz ${ }^{1}$, Dawid Romek ${ }^{1}$, and Przemysław Rogoziński ${ }^{1}$ \\ ${ }^{1}$ Poznan University of Technology, Institute of Machines and Motor Vehicles, Marii Sklodowskiej 5 \\ sq. 60-965 Poznan, Poland
}

\begin{abstract}
Cultivators are machines used among others to open and smooth out the surface of the ploughland and to mix mineral fertilizers with soil. The article presents a design of a cultivator mounted on an agricultural tractor with a power of up to $20 \mathrm{~kW}$. The main design assumption mainly focuses on keeping the weight of the device low, while ensuring the required durability. Moreover, the design makes it possible to attach it to the three-point linkage in a category 1 tractor. The drafted design was subjected to the MES analysis, according to which, the maximum travel of the cultivator frame does not exceed $1.3 \mathrm{~mm}$, and the stress typically reaches the level of $40 \mathrm{MPa}$ and does not exceed the stress permissible for the E295 steel. An analysis of the costs of manufacturing the cultivator was also performed and on its basis, it was found that the price should not exceed PLN 1,800.
\end{abstract}

Keywords: agricultural tractor, cultivator, soil

\section{Introduction}

Modern agriculture benefits from a number of machines tasked with preparing the soil as well as possible for the cultivation of the ploughland. The basic activities performed by farmers include ploughing, opening up the top layer of the soil, and mechanical elimination of weeds. For these activities, tools such as harrows, cultivators, and drags are used. Cultivators have various designs, from those mounted to the tractor through to the most popular ones that are attached to the three-point linkage. The attached cultivators have been known and used for years. Their examples are provided in Fig. 1, but most of them are characterized by considerable weight of about $200 \mathrm{~kg}$.

Currently, the agricultural and fruit farming industry shows a tendency to use various types of tractors for auxiliary works, e.g. mini tractors supposed to support and substitute the heavy and basic tractors whenever their weight and size could interfere with proper performance of work. Tractors of this type are used with light and smaller cultivator designs. The mini tractors are imported to Poland in large numbers from Japan, where they

\footnotetext{
* Corresponding author: jaroslaw.selech@put.poznan.pl

Reviewers: Wiestawa Piekarska, Ján Vavro
} 
are very popular, however, there is a shortage of suitable accompanying machines. This paper responds to these needs.

a)

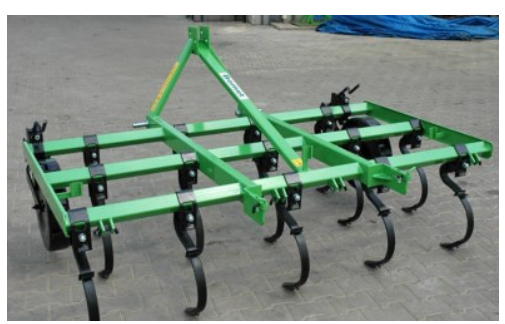

c)

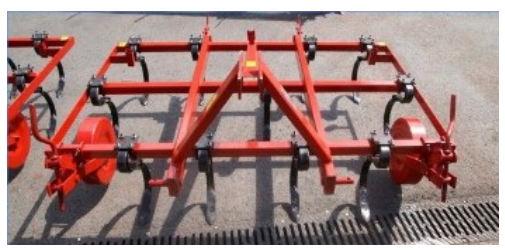

b)

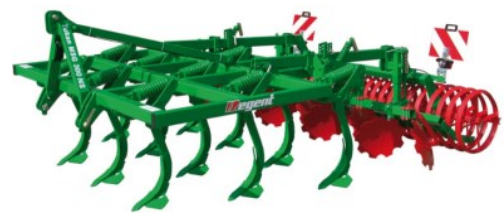

d)

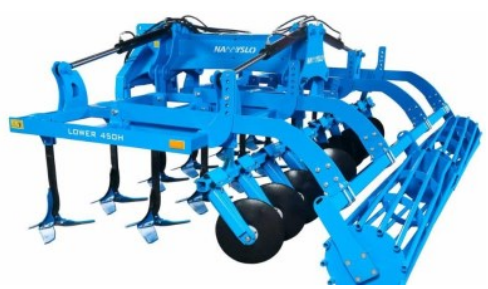

Fig. 1. Cultivator design solutions; a) Bomet [1], b) Regent [2], c) U 454/1 [3], d) Lower 450 [4]

The paper presents a draft design of a cultivator accommodated for such tractors. The design should meet the following requirements:

- total weight below $170 \mathrm{~kg}$,

- use of inexpensive materials in the form of E295 steel sections,

- working width $2 \mathrm{~m}$,

- working speed $10 \mathrm{~km} / \mathrm{h}$, transport speed up to $20 \mathrm{~km} / \mathrm{h}$,

- working depth $130 \mathrm{~mm}$,

- accommodated to be mounted on a three-point linkage in accordance with category 1 of the DIN ISO 730-1 standard.

\section{Cultivator design}

The essential elements of the designed cultivator presented in Fig. 2 include:

- supporting frame (1),

- copying (gauge) wheels (2),

- light spring teeth with cultivator points (3),

- string shaft (4).

The main element of the designed cultivator is the supporting frame consisting of two longitudinal members made of $80 \times 60 \times 4 \mathrm{~mm}$ steel box sections and three rows of $50 \times 50 \times 3$ $\mathrm{mm}$ crossbeams welded to the longitudinal members. The side faces of the frame made of a $70 \times 8 \mathrm{~mm}$ flat steel section are welded on the sides to the ends of transverse sections. In the front section of the frame, there are two pins and the top point of the linkage, which constitute the three-point linkage of the cultivator. It was made in accordance with the DIN ISO 730-1 standard for category 1. 


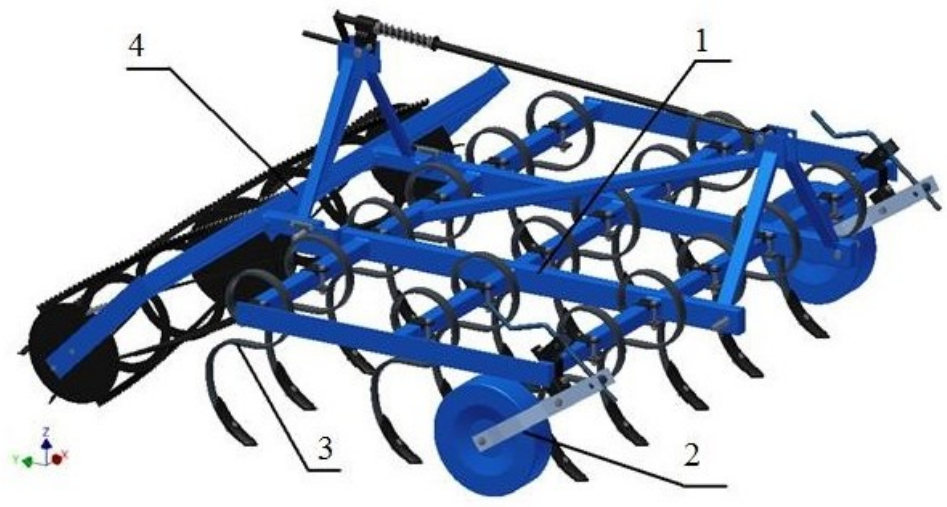

Fig. 2. Cultivator design with basic elements [5]; 1 - supporting frame, 2 - copying (gauge) wheels, 3 - spring teeth, 4 - string shaft

The top section of the three-point linkage system is connected with the rear crossbeam of the frame with a $60 \times 40 \times 4 \mathrm{~mm}$ closed box section, which acts as an angle strut, thanks to which the structure is reinforced and braced. The designed cultivator frame is depicted in Fig. 3.

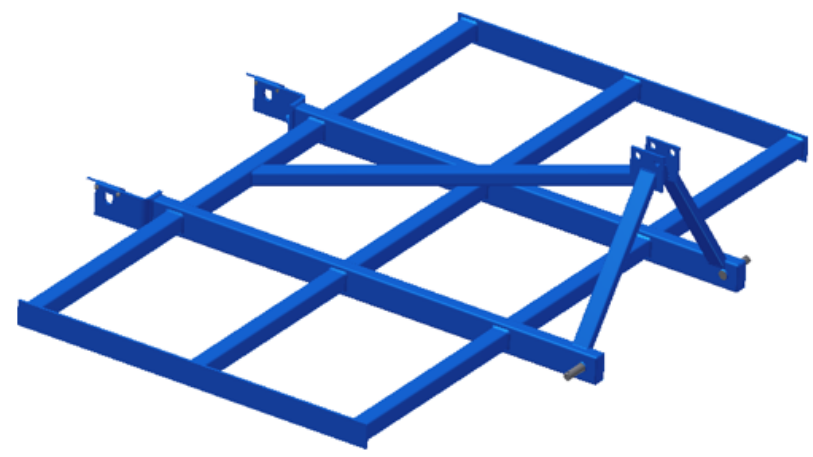

Fig. 3. Cultivator frame [5]

The mounting points for attaching a cooperating tool are welded to the rear section of the frame. The mounting point is made of a flat bar $10 \mathrm{~mm}$ in thickness and $90 \mathrm{~mm}$ in height, with a point provided for seating the pin of the cooperating tool. The mounting safeguard consists in screwing down a locking device securing the pivot of the cooperating tool in place. The concept of mounting the cooperating tool is provided in Fig. 4.

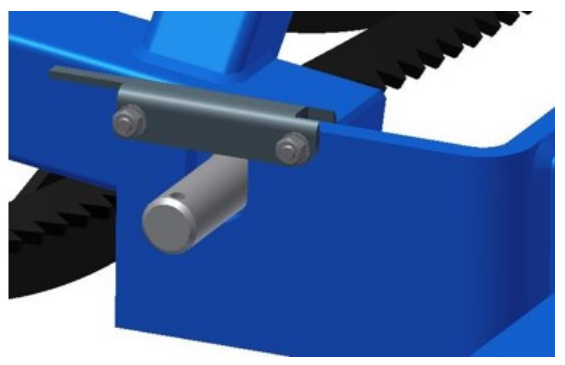

Fig. 4. Closed locking device of the cooperating tool [5] 
Light spring teeth ending with replaceable cultivator points are the working elements of the cultivator. When in operation, they vibrate strongly, which improves their effect on the soil and makes it possible to extract root-propagated weeds to the surface without excessive tearing. They were selected from the Kongskilde catalogue. The tooth is fixed (1) - Fig. $5-$ by screwing it down with an M12×80 screw (2) to the yoke (3), which is seated on the frame crossbeams. The teeth are spaced at $345 \mathrm{~mm}$ in three rows.

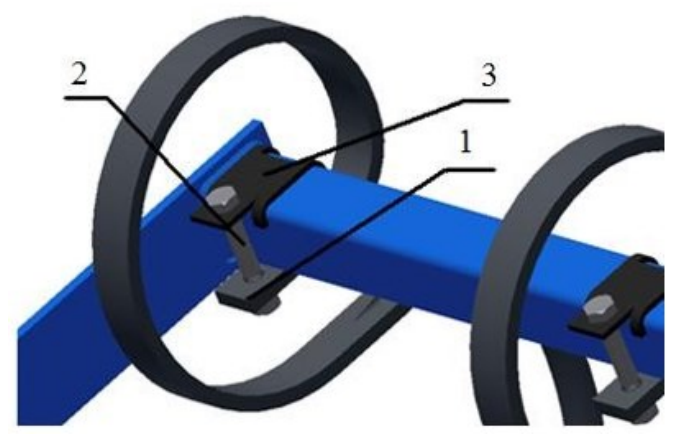

Fig. 5. The method of fixing the tooth to the frame [5]; 1 - tooth, 2 - screw, 3 - yoke

The elements responsible for adjusting he cultivator's working depth (Fig. 6) are support wheels (1) seated in levers (2). The assembly is mounted on the sides of the frame with clamps (3). The diameter of the copying (gauge) wheels is $350 \mathrm{~mm}$, whereas their width is $100 \mathrm{~mm}$. The wheels are fitted with greaseless slide bearings. The working depth is adjusted by turning the crank (4) with a screw mechanism.

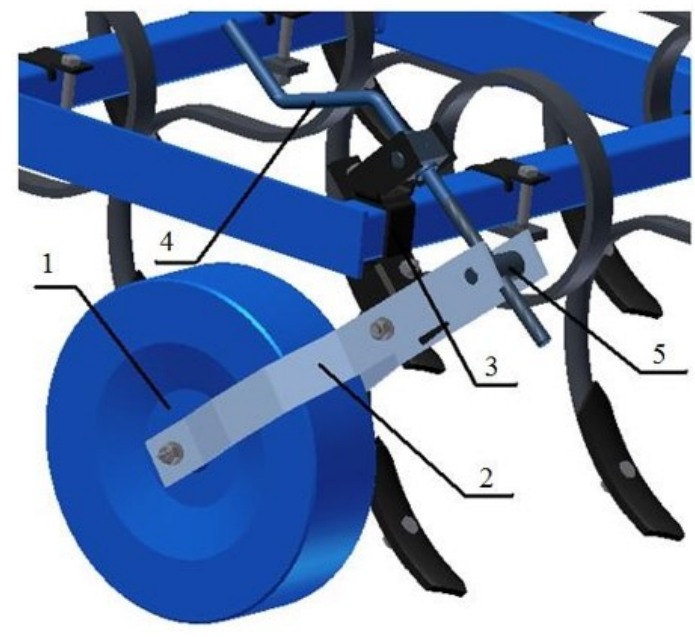

Fig. 6. Support wheels responsible for adjusting the working depth [5]; 1 - wheel, 2 - lever, 3 - clamp, 4 - crank, 5 - nut

The string shaft is mounted on the rear section of the cultivator frame. The top point of the shaft linkage is fixed to the cultivator frame with an adjustable connecting member. The shaft design includes a frame made of sections and two string shafts welded from $5 \mathrm{~mm}$ thick steel sheet. The diameter of a single shaft is $350 \mathrm{~mm}$, whereas its width is $980 \mathrm{~mm}$. The string shaft is seated on self-aligning ball bearings with reinforced sealing. SKF FYTJ $20 \mathrm{TF}$ bearing units were used. The entire structure of the cultivator was modelled using the CAD Autodesk-Inventor software. It was also used to perform all the strength analyses. 


\section{FEM analysis}

The MES analysis was performed using the stress analysis tool of the Autodesk Inventor Professional 2011 software. The main element subjected to analysis was the frame, the results are provided in Fig. 7-9. The cultivator frame was supported in exactly the same way as when the cultivator is attached to the three-point linkage system of a tractor. The torques and forces reflecting the operating conditions were applied to the points of tooth installation. Reduced load in the form of a torque of $84 \mathrm{Nm}$ and the resulting force of $200 \mathrm{~N}$ was applied in the place of tooth installation.

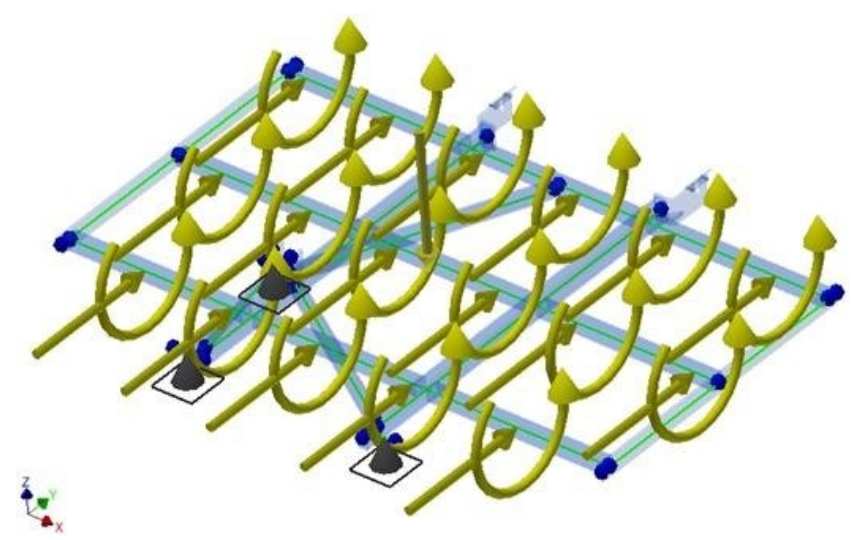

Fig. 7. The method of supporting and loading the cultivator support frame [5]

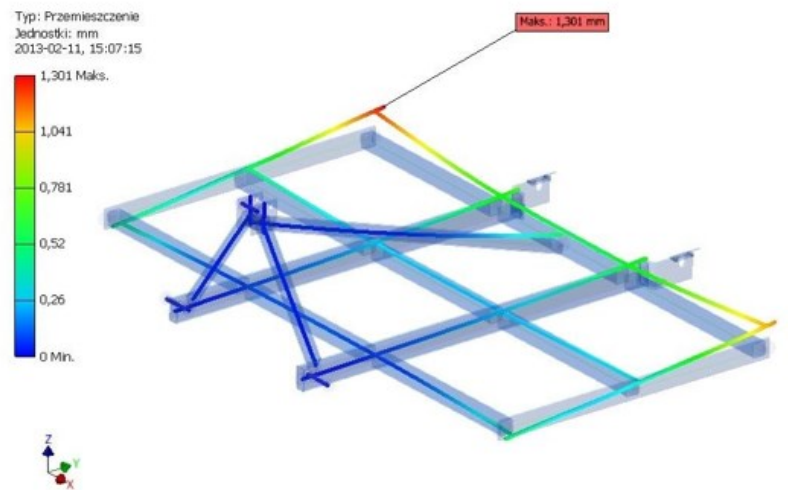

Fig. 8. Displacements occurring in the support frame of the cultivator [5]

The reduced loads were calculated using a simplified method based on the available literature [6].

The frame was automatically modelled for calculations using 1D beam elements, because solid elements are not suitable in this case and slow down the calculations without improving their accuracy. FEM calculations were performed only in terms of statics and only in one case in terms of the load, i.e. in the working position for the maximum working depth. Because the spring teeth and the strong dampening characteristics of the soil largely eliminate the dynamic effects, the authors omitted the dynamic analysis of the structure. The surplus dynamic forces occurring when e.g. a stone is struck can be expressed in the safety factor. Because the frame is very light, the gravitational load in the transport position is insignificant. 


\section{Analysis results}

The maximum displacements of the supporting frame are located in the left rear corner and total $1.3 \mathrm{~mm}$. Different displacement values of the right and left sides of the supporting frame result from asymmetric loading placed by the spring teeth. The maximum normal stresses are located in the rear section of the frame, at the point where the angle strut connects with the last crossbeam of the structure. They are $40 \mathrm{MPa}$ and are considerably below the permissible stress assumed for steel type E295 used for the construction of the cultivator's supporting frame.

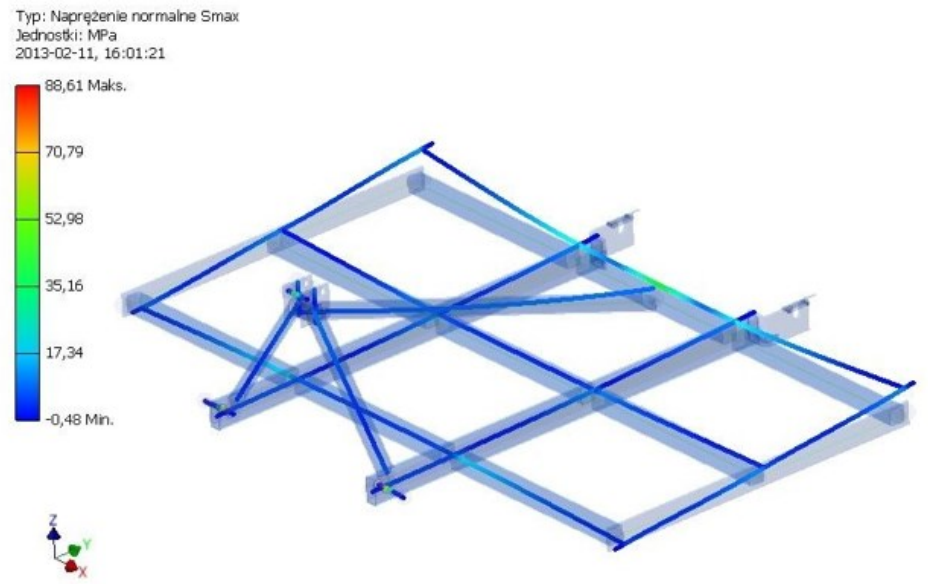

Fig. 9. Normal stresses of the cultivator frame [5]

\section{Conclusions}

The article presents an elaboration of the concept and an analysis of the design of a cultivator with a light and strong frame which makes it possible to attach it to small agricultural tractors. Cultivators ensure good opening and pulverization of the soil and enable mixing of mineral fertilizers with the soil. The adopted concept of the machine meets the assumptions, especially in terms of the strength of the frame of the structure, i.e. its load-bearing element. The main costs related to the construction of the cultivator in accordance with this design include above all the cost of ready components and the cost of manufacturing the steel frame using appropriate sections. The ready parts, such as bearings, bearing mountings, cultivator teeth with points, and support wheels, were selected from manufacturer catalogues and their total price should not exceed PLN 1,000. The cost of manufacturing the frame with suitable sections and treating them against corrosion should total about PLN 700. Furthermore, the costs related to the production of the spring shaft (sheet - PLN 100) should be added. Because the designed solution is intended for small agricultural tractors, a wider frame for larger agricultural tractors can be designed at subsequent stages, which will make it possible to install more teeth.

The device's innovation is based on a universal hitch and aggregation of the cultivator together with other machines using three-point linkage. The cultivator can be equipped with attachments of different sizes of hooks. An additional innovation is the type of attachment of the cultivator's tooth which are fixed with one centrally arranged screw. Also the cultivator teeth made of spring steel have a different shape than the currently manufactured devices. Designed structure of cultivator is about $10 \%$ lighter than the devices currently used on the market. The lightness and simplicity of the design cultivator causes the 
opportunity to reduce its cost which is particularly important. In Division of Heavy Machinery of Poznan University of Technology a database of such freely available structures is created and this project is one of the element.

The idea of creating such a base of ready-made projects comes from the assumption that ready-made agricultural machines can be produced in small workshops, even on the farm, by assembling them from ready-made high-quality components manufactured by specialized producers. Such a production of machine by providing virtual ready-made projects in the virtual space would allow for their better adjustment to specific needs, reduction of costs related to transport, trade and monopolisation of production by large corporations. This trend is often visible in the form of forced by the needs of various adaptations of machines made by farmers themselves. In addition, project of the cultivator is an important didactic example for students of Division of Heavy Machinery.

\section{References}

1. https://sprzedajemy.pl/kultywator-bomet-2-5-1-8-2-1-2-8-3-0-3-2-3-2r-3-6r-wolarozaniecka-2-e30984-nr41949807 - accessed in 7.2018

2. http://www.langner-maszyny.pl/regent/kultywatory,c25/\# - accessed in 7.2018

3. http://namyslo.com.pl/produkt/kultywator-u-4541-zawieszany-ciagnikowy-11-zebowszerokosc-robocza-18-rama-50-x-50/ - accessed in 7.2018

4. https://www.mascus.pl/rolnictwo/uzywane-kultywatory/namyslo-kultywator-lower450h-cultivator-grubber/rhroolvq.html - accessed in 7.2018

5. P. Rogozinski, Projekt kultywatora zawieszanego na ciagniku o mocy do $20 \mathrm{~kW}$. Diploma thesis (2013)

6. H. Bernacki, J. Haman, Cz. Kanafojski, Teoria i konstrukcja maszyn rolniczych. T. I. PWRiL (1967) 